\title{
To Study Visual Outcome, Endothelial Cell Loss and Complications after Retropupillary Iris Claw Lens Implantation in Patients with Deficient Posterior Capsule
}

\author{
Satyaprakash S1, Arun KS ${ }^{1 *}$, Shivangi S², Kamaljeet $\mathbf{S}^{1}$, Jagriti $\mathbf{R}^{1}$ and \\ Arti $S^{1}$ \\ ${ }^{1}$ Department of Ophthalmology, Regional Institute of Ophthalmology at Govt. M. D. Eye \\ Hospital, India \\ ${ }^{2}$ Himalayan Institute of Medical Sciences Dehradun, India
}

Research Article

Volume 3 Issue 3

Received Date: May 10, 2018

Published Date: June 07, 2018

*Corresponding author: Arun Kumar singh, Department of Ophthalmology, Regional Institute of Ophthalmology at Govt. M. D. Eye Hospital, Dr. Katju Road, Allahabad - 211003, Uttar Pradesh, India, Tel: +919452544700; Email: arunsingh.gsvm@gmail.com

\section{Abstract}

Purpose: To study visual outcome, endothelial cell loss and complications after retropupillary Iris claw lens implantation in patients with deficient posterior capsule.

Patients and methods: This prospective study included 33 patients who underwent retropupillary iris claw lens implantation in patients with posterior deficient capsule.

Results: The mean Preop LogMAR was 0.5338 while it improved to 0.3149, 3 month postoperatively which is equivalent to $6 / 12$. The mean endothelial cell loss was $14.95 \%$. There was no significant increase in IOP. Macular oedema was observed in 18 (54.54\%) cases which decreased in follow up, pigment dispersion was seen in 12 (36.36\%) cases. No disenclavation was seen in any case.

Conclusion: Retropupillary Iris Claw lens implantation is less time consuming, cost effective, predictable and safe procedure capable of delivering good visual outcomes and associated with fewer complications.

Keywords: Iris Claw Lens; Retropupillary; Aphakia; Enclavation

Abbreviation: ACIOL: Anterior Chamber Intraocular Lens; SFIOL: Scleral Fixated Intraocular Lens; PBK: Pseudophakic Bullous Keratopathy; UCVA: Uncorrected
Visual Acuity; BCVA: Best Corrected Visual Acuity; OCT: Optical Coherence Tomogram. 


\section{Open Access Journal of Ophthalmology}

\section{Introduction}

Cataract surgery has evolved many folds in all these years but sometimes posterior chamber intraocular lens (PCIOL) cannot be implanted after the cataract extraction.

In cases of Aphakia, posterior chamber IOL dislocation, Large posterior capsular rent or Whole bag removal, Marfan syndrome / ectopia lentis, Large zonular dialysis, Traumatic dislocation of crystalline lens, there may be insufficient posterior capsular support for PCIOL implantation either in the capsular bag or sulcus.

The available treatment options are anterior chamber intraocular lens (ACIOL), a scleral fixated intraocular lens (SFIOL) or an iris fixated IOL. The use of ACIOLs within iridocorneal angle has often been reported to cause endothelial cell loss and pseudophakic bullous keratopathy (PBK) [1,2]. The scleral fixation of posterior chamber IOLs has several disadvantages such as difficult suture technique, longer surgical time and complications including hypotony, possible intraoperative bleeding, damage to the ciliary body, Choroidal haemorrhage, retinal detachment, vitreous incarceration and cystoid macular oedema.

The Iris Claw lens lens was designed by Prof. Jan G.F Worst in 1978 [3-8]. It was a plano convex type of lens with a circular aperture between optic and haptic [9]. A modified convex-concave version with vaulted design was introduced in 1996 to increase the distance between the IOL and the corneal endothelium; this model has since been in common use. Iris-claw lenses can be fixated to the iris either in the anterior chamber or in the posterior chamber. However with implantation of Iris claw lens in anterior chamber there is risk of reduction in endothelial cell count which can lead to pseudophakic bullous keratopathy. The haptics of the lens are attached to the midperipheral iris stroma which is immobile, thus allowing the pupil unrestricted ability to dilate and constrict.

The technique of retro pupillary iris fixation of iris claw lens which was first reported by Andreas Mohr in 2002, offers several advantages [10]. It combines the benefit of posterior chamber IOL implantation with a low-risk, cost effective, less time consuming method of surgery [10]. IOL haptics and some parts of optic are behind the iris, thus better cosmetically than anterior chamber implants. Retropupillary fixation of iris-claw lenses enhances stability, prevents tilting of the lens and reduces the glare phenomenon, which is characteristic of the anterior chamber IOL implants. There are also few disadvantages like disenclavation, pupillary deformity and iris atrophy.

Several studies have been done to study the visual outcome, complications, advantages and disadvantages after RPICIOL and have been compared to the SFIOL and ACIOL. Lately there has been emphasis on evaluating endothelial cell loss after RPICIOL. In this regard, we have analysed mainly the visual outcome, endothelial cell loss and complications of retropupillary iris claw lenses with special emphasis on the documentation of endothelial cell count preoperatively and at all follow up visits.

\section{Material and Methods}

The study was carried out at Tertiary Eye care centre in Allahabad after taking permission from ethical committee of M.L.N. Medical College, Allahabad. As per hospital protocol, written informed consent was obtained from all patients before all the surgical procedures that they underwent. This prospective cohort study included 33 eyes of 33 patients who underwent retropupillary iris claw lens implantation in patients with posterior deficient capsule. The indications of the Iris claw lens implantation in our study are shown in Table 1 . Chi square test and student paired $\mathrm{T}$ test were used for statistical analysis. The value of $\mathrm{p}<0.05$ was considered statistically significant.

\begin{tabular}{|c|c|c|}
\hline Indication & No & \% \\
\hline Aphakia & 21 & 63.63 \\
\hline Dislacated IOL & 6 & 18.18 \\
\hline PCIOL in Anterior chamber & 6 & 18.18 \\
\hline
\end{tabular}

Table 1: The indications of the Iris claw lens implantation in our study.

The inclusion criteria included patients with posterior deficient capsule, endothelial cell count more than 1000 cells, and BCVA of 6/60 or better on Snellen chart. The exclusion criteria included patients with decompensated cornea, insufficient iris tissue and posterior segment pathologies. Preoperatively uncorrected visual acuity (UCVA) and best corrected visual acuity (BCVA) of all the patients was taken and following examinations were done:

a. Slit-lamp examination.

b. Keratometry and A scan, IOL power calculation by SRK/T formula with a constant of 115.

c. Retinal evaluation with $90 \mathrm{D}$ and indirect ophthalmoscopy. 


\section{Open Access Journal of Ophthalmology}

d. Endothelial cell count by specular microscopy (Topcon SP-1P).

e. Non contact Tonometry (Nidek - NT 510 NCT).

f. Optical coherence tomography (Carl Zeiss Meditech, Dublin, CA, USA).

\section{Surgical Technique}

Retropupillary iris claw lens implantation was performed by the same surgeon (SPS) in the operating room with all aseptic precautions using local anesthesia. A superior $5.5 \mathrm{~mm}$ sclera - corneal/clear corneal incision is made. Two paracentesis are made $90^{\circ}$ from the main incision. Intracameral pilocarpine is injected to constrict pupil. Iris claw IOL is introduced into the anterior chamber through main incision under air. Viscoelastic (2\% HPMC) is injected at each stage to maintain anterior chamber. Holding the optic with a special lens holding forceps with flat and broad ends, one haptic is tilted down and pushed under the iris. Simultaneously an Iris repositor / sinsky hook is passed through the paracentesis on the same side. Now with the simultaneous upward movement of the lens haptic and downward movement of the sinsky hook, iris is enclavated in the lens haptic claw. Similarly enclavation is done in another side. Anterior vitrectomy was done in most of the cases. Viscoelastic is aspirated with Simcoe's canula and anterior chamber is formed (Figures $1 \& 2$ ).

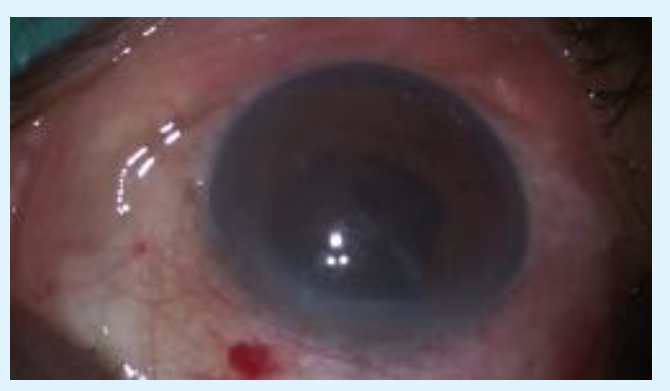

Preop

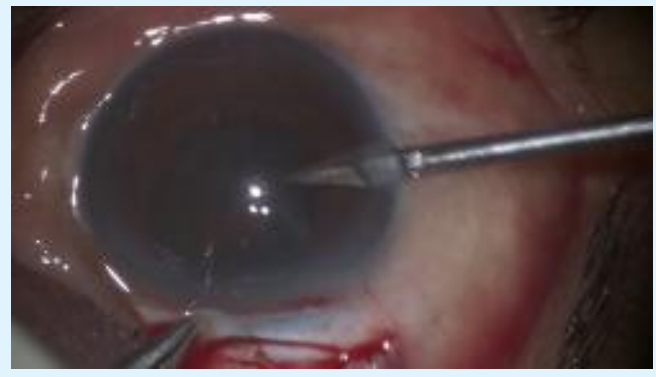

Making side ports

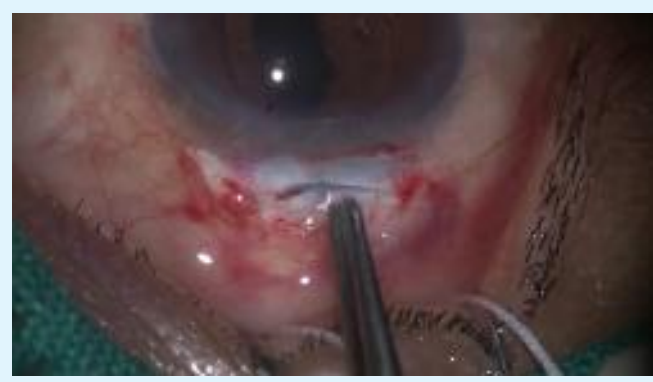

Putting Iris claw lens under air

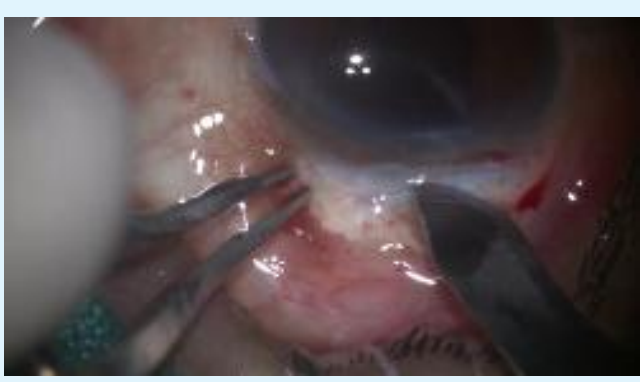

Marking 5.5mm incision

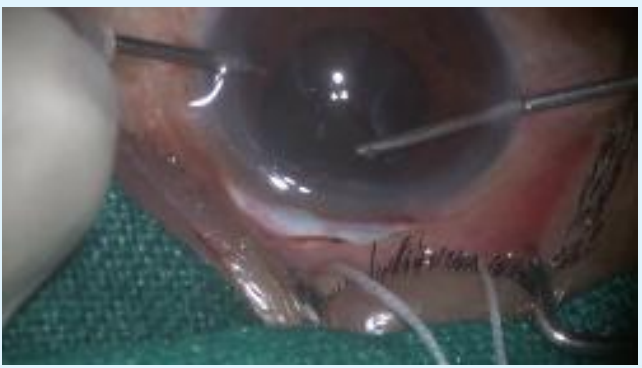

Anterior Vitrectomy

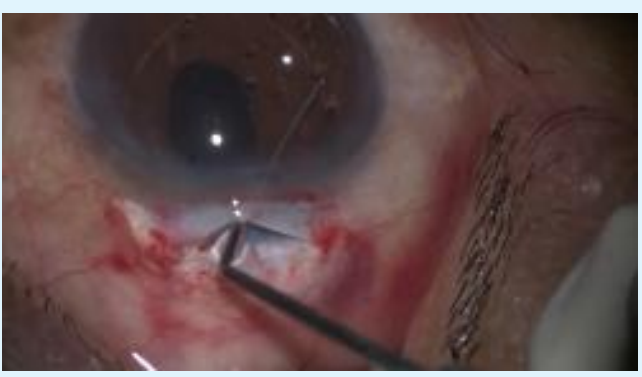

Rotating the IOL 90 degree 


\section{Open Access Journal of Ophthalmology}
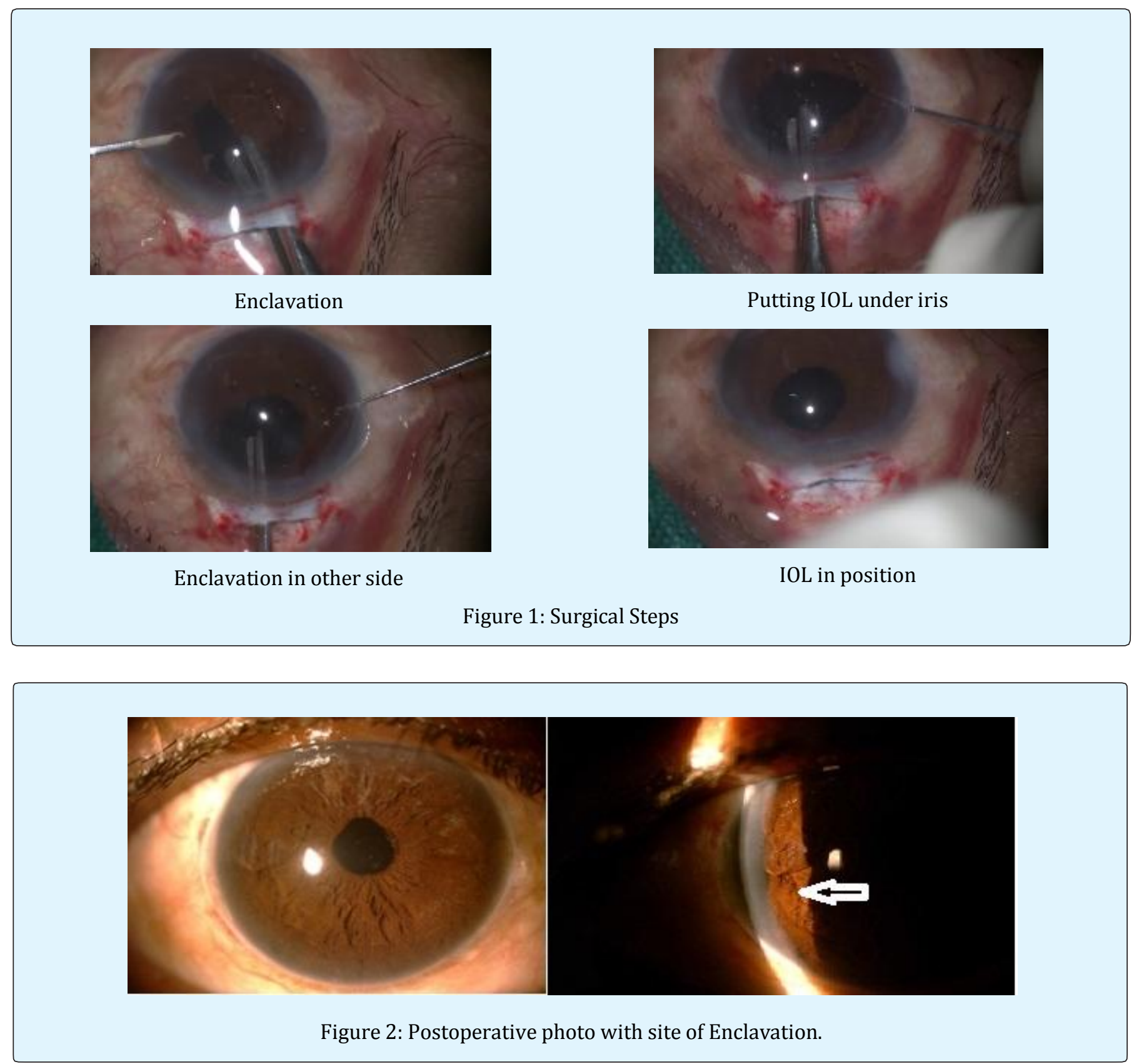

On the first postoperative day, the patient was examined specifically to assess the IOL centration, endothelial cell loss with the help of specular microscopy and macular oedema with the help of optical coherence tomogram (OCT). These were repeated at every follow up visit. A standard postoperative treatment of topical antibiotics (moxifloxacin 0.5\% eye drops and tobramycin $0.3 \%$ eye drops ) given for 4 weeks and tapering doses of topical steroids (prednisolone acetate 1\%) given for 4 weeks was followed.

\section{Follow-Up}

Postoperative follow-up visits were held $24 \mathrm{hrs}$ after surgery, 1 week, 4 weeks and 3 months after surgery. At every follow up visit following examinations were done:

- Best Corrected Visual Acuity (BCVA).

- Non Contact Tonometry. 


\section{Open Access Journal of Ophthalmology}

- $90 \mathrm{D}$ and indirect ophthalmoscopy.

- Apecular microscopy.

- Optical coherence tomography.

\section{Observation \& Results}

We included 33 eyes of 33 patients who underwent retropupillary Iris claw lens implantation. The mean age of the patients was 62.18 years (45-80 years) with 9 $(27.27 \%)$ males and 24 (72.72 \%) females. The Age distribution is shown in Figure 3.

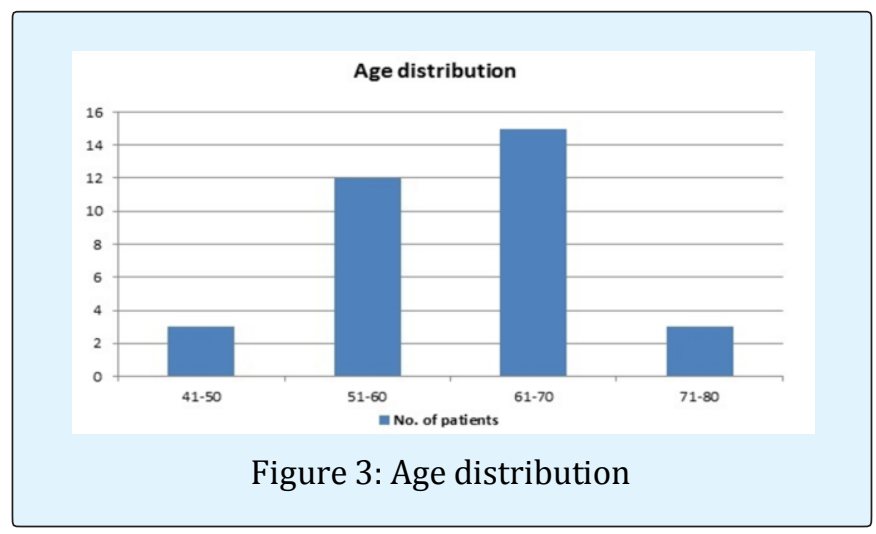

\section{Visual Outcome}

The mean best corrected LogMAR preoperatively was $0.5338 \pm 0.2188$ (range from 0.176 to 0.778 ) while at the end of the follow-up period the mean post-operative bestcorrected $\operatorname{LogMAR}$ was $0.3149 \pm 0.1729$ (range from 0 to 0.602) (Figure 4).

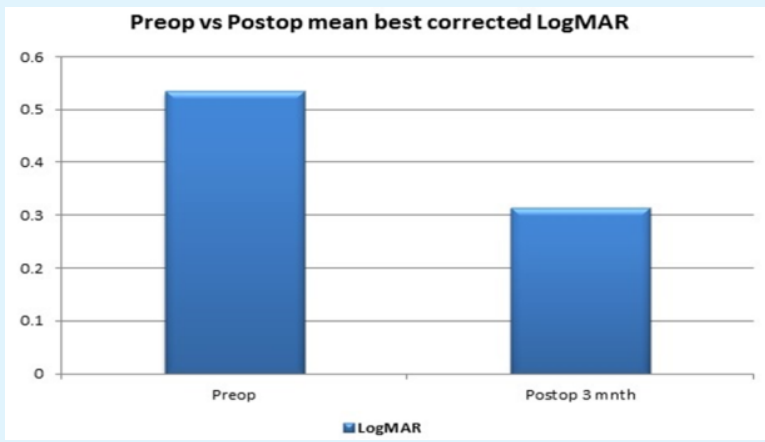

Figure 4: Preop vs Postop mean best corrected LogMAR

Preoperatively only 6 patients $(18.18 \%)$ had visual acuity better than $6 / 12$ while after 3 months 21 patients (63.63 \%) had visual acuity better than 6/12 (Figure 5).
Preop vs Postop 3 month BCVA $\geq 6 / 12$

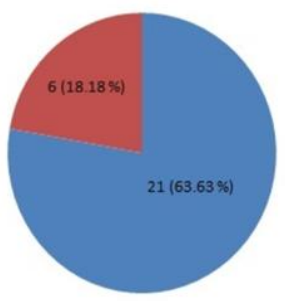

Postop

mpreop

Figure 5: Preop vs Postop 3 month BCVA $\geq 6 / 12$

On applying the Chi-Square test to Table 2, $\mathrm{p}$ value was 0.000033 which is highly significant at $\mathrm{P} \leq 0.05$.

\begin{tabular}{|c|c|c|}
\hline BCVA & Preop & 3 Months Postop \\
\hline$\geq 6 / 12$ & 6 & 21 \\
\hline $6 / 12-6 / 24$ & 15 & 12 \\
\hline$<6 / 24$ & 12 & 0 \\
\hline
\end{tabular}

Table 2: BCVA preop vs. 3 months postop

\section{Endothelial Cell loss}

The mean preoperative endothelial cell count was $2207.18 \pm 615.29$ cells $/ \mathrm{mm} 2$ which decreased to 1877.91 \pm 569.55 cells $/ \mathrm{mm}^{2}$ after 3 months of follow up, with mean endothelial cell loss of $14.95 \%$ (Figure 6).

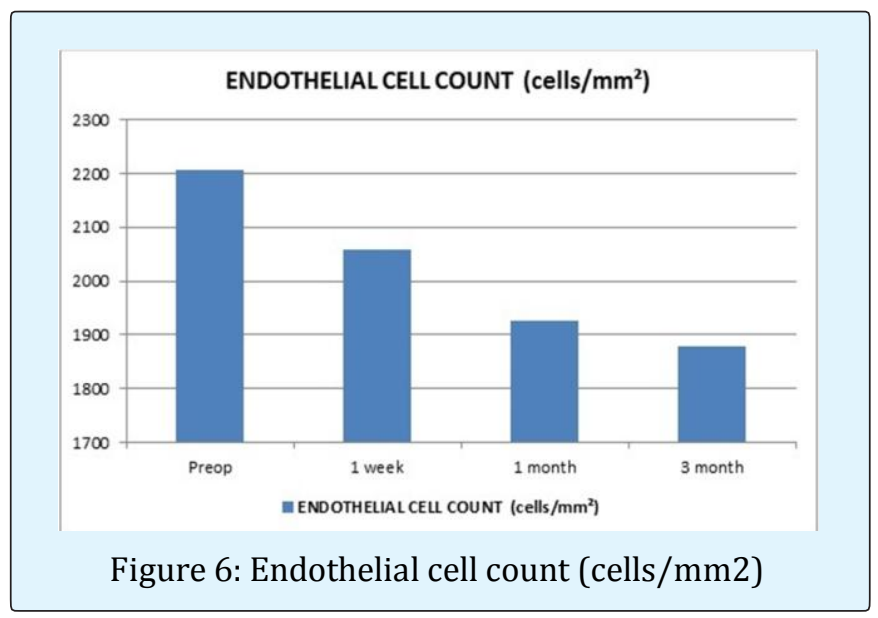

It is clear from the Table 3 that maximum endothelial cell loss occurs in the first week postoperatively which indicates more towards the intraoperative endothelial cell loss and not due to the Iris claw lens. 


\section{Open Access Journal of Ophthalmology}

\begin{tabular}{|c|c|c|c|c|c|c|c|}
\hline & Preop & $\begin{array}{c}\text { Post op 1 } \\
\text { week }\end{array}$ & \% ECL & $\begin{array}{c}\text { Post op 1 } \\
\text { Month }\end{array}$ & \% ECL & $\begin{array}{c}\text { Post op 3 } \\
\text { Month }\end{array}$ & $\begin{array}{c}\text { \% } \\
\text { ECL }\end{array}$ \\
\hline $\begin{array}{c}\text { Mean endothelial cell } \\
\text { count (cells } / \mathrm{mm}^{2} \text { ) }\end{array}$ & $\begin{array}{c}2207.182 \\
\pm 615.289\end{array}$ & $\begin{array}{c}2059.182 \\
\pm 606.037\end{array}$ & $6.07 \%$ & $\begin{array}{c}1926.818 \\
\pm 579.22 .\end{array}$ & $12.73 \%$ & $\begin{array}{c}1877.909 \\
\pm 569.553\end{array}$ & $\begin{array}{c}14.95 \\
\%\end{array}$ \\
\hline
\end{tabular}

Table 3: Mean endothelial cell count

\section{Complications}

The complications were divided into 3 parts:
Intraoperative, Perioperative $(<1$ week $)$ and Postoperative ( $>1$ week) which are summarised in Table 4.

\begin{tabular}{|c|c|c|c|c|c|c|c|c|c|c|c|}
\hline \multicolumn{3}{|c|}{ Intraoperative } & \multicolumn{3}{|c|}{ Perioperative $<1$ wk } & \multicolumn{3}{|c|}{ Postoperative 1wk -1 mnth } & \multicolumn{3}{|c|}{$\begin{array}{l}\text { Postoperative } 1 \text { mnth - } 3 \\
\text { mnth }\end{array}$} \\
\hline Complication & No. & $\%$ & Complication & No. & $\%$ & Complication & No. & $\%$ & Complication & No. & $\%$ \\
\hline \multirow{5}{*}{ Bleeding } & \multirow{5}{*}{3} & \multirow{5}{*}{9.09} & Macular oedema & 18 & 54.54 & Macular oedema & 9 & 27.27 & Macular oedema & 3 & 9.09 \\
\hline & & & Uveitis & 9 & 27.27 & Uveitis & 3 & 9.09 & \multirow{2}{*}{ Pupil Ovalisation } & \multirow{2}{*}{6} & \multirow{2}{*}{18.18} \\
\hline & & & Pupil Ovalisation & 15 & 45.45 & Pupil Ovalisation & 6 & 18.18 & & & \\
\hline & & & IOL decentration & 3 & 9.09 & IOL decentration & 3 & 9.09 & IOL decentration & 3 & 9.09 \\
\hline & & & $\begin{array}{l}\text { Slight elavation in } \\
\text { IOP }\end{array}$ & 11 & 33.33 & $\begin{array}{c}\text { Slight elavation in } \\
\text { IOP }\end{array}$ & 12 & 36.36 & $\begin{array}{l}\text { Pigment } \\
\text { dispersion }\end{array}$ & 12 & 36.36 \\
\hline
\end{tabular}

Table 4: Complications

\section{Discussion}

The IOL options available in cases with deficient posterior capsule are ACIOL, SFIOL and Iris fixated lenses. ACIOL implantation is easy, less time consuming but avoided due to postoperative endothelial cell loss leading to psudophakic bullous keratopathy in many cases. SFIOL implantation respect the anatomy of eye but it is technically challenging, time consuming and associated with many complications [11]. Retropupillary iris claw lens implantation combines the benefits of both ACIOL and SFIOL. The retropupillary fixated IOL does not prevent pupil dilation for posterior segment examination and treatment purposes. It has advantage of posterior chamber implantation which is easy having a short learning curve, less time consuming and associated with fewer complications [12,13].

\section{Visual Acuity}

In our series $24(72.72 \%)$ patients improved their BCVA while rest of the patients had unchanged visual acuity [14-16]. Other studies also report an improvement in visual acuity after implantation of a retropupillary Iris claw lens. Preoperatively, $6(18.18 \%)$ eyes had BSCVA $\geq 20 / 40$ while 3 months postoperatively, 21 (63.63\%) eyes had BSCVA $\geq 20 / 40[5,15]$.
In the series of De Silva et al, $68 \%$ of all eyes achieved a final BSCVA of $6 / 12(20 / 40)$ or better, and $88.7 \%$ of eyes with no other pathology limiting vision achieved this level of vision. Mohr et al saw visual improvement in 27 patients (56.2\%), an unchanged visual acuity in 18 patients $(37.5 \%)$ while there was decrease in visual acuity in 3 patients (6.2\%) [16]. these results are comparable with previous study of iris-claw IOLs and secondary open-loop anterior chamber IOLs $(60-77 \%$ of eyes with a BSCVA $\geq 20 / 40$ ), and secondary scleralsutured posterior chamber IOLs (53.8-77.8\% of eyes with a BSCVA $\geq 20 / 40)$ or secondary iris-sutured PC IOLs $(60 \%$ to $67 \%$ ) [10].

\section{Endothelial Cell Loss}

It is a well-established fact that there is endothelial cell loss after all cataract surgeries. The main concern when implanting anterior chamber IOLs is progressive loss of corneal endothelial cells followed by corneal decompensation [17]. The posterior position of the irisclaw IOL and the greater distance from the endothelium makes this technique safer [11]. In this study, we found a statistically significant decrease in endothelial cell count during the first 3 months (14.51\%) [15]. Menezo, et al. found no difference in endothelial cell loss after Iris claw lens implantation as compared with scleral-fixated lenses. Although the decrease in endothelial cell count does not 


\section{Open Access Journal of Ophthalmology}

seem clinically significant in most cases, as we did not encounter any case of corneal decompensation, De Silva, et al. reported that corneal decompensation occurred in $1.7 \%$ of eyes [18]. Koss and Kohnen reported a cumulative endothelial cell loss of $10.5 \%$ in their study after implantation of iris claw lenses in anterior chamber [16]. The cell loss occurred predominantly during the first year $(7.78 \%)$ [19].

The longest follow-up period of any series was 9.5 years in 3 children who underwent congenital cataract extraction following Iris claw lens implantation, and reported no difference in endothelial cell count when compared to the unoperated eye [20]. In a study by Raghvendra Rao, et al. postoperatively, at the end of 6 months, endothelial cell loss was 8.96\% [21].

\section{Complications}

In 2002, Mohr et al. first reported retropupillary fixation of iris claw lenses in 48 patients [22]. After 1 year there was loss of iris pigment with deposition over the lens in four patients and cystoid macular edema in two patients.

Overall, the incidence of complications in our study is similar to other studies, and are generally related to a preexisting eye disease or predisposing factor rather than to the IOL implantation itself. We saw elevated IOP in 11 cases and all were managed medically which is in accordance with previous studies $[16,19,20]$. There was no case of pupillary block in spite of no peripheral iridectomies which can be due to posterior vaulting of this lens resulting in adequate space between the iris and lens optic for the flow of aqueous humour [23,24].

Iris claw IOLs may be particularly useful in eyes with a compromised angle, in which an AC IOL may not be suitable. Thorough anterior vitrectomy if vitreous is present in the anterior chamber should be done in all cases. In most cases, IOP returns to preoperative values after withdrawal of treatment. There were no cases of hyphaema, hypotony and pupillary block in our study [18]. According to Gonnerman incidence of postoperative macular edema was $8.7 \%$ after 6 to 7 months of Iris claw lens implantation. In a study done by De Silva on ICIOL two patients had CME of which one had chronic CME [12]. We didn't find any case of CME. But slight macular oedema in 9 cases (27.27\%) was seen in our series, which subsided during the follow up period [16]. With the use of secondary open-loop AC IOLs, the CME rate varied from $0 \%$ to $33 \%$. The incidence of CME after sulcussutured PC IOLs was $0 \%$ to $7.6 \%$ and after iris-sutured PC IOLs, $0 \%$ to $16.7 \%[24,25]$.

Studies have estimated a rate of IOL dislocation due to suture breakage in scleral-fixated PC of between $7.8 \%$ and 27.9\%; No dislocation was seen in our study $[4,6,18]$. Gonnerman found dislocation rate upto $8.7 \%$ in his study $[25,26]$. Other studies of posterior-fixated iris-claw IOLs report a dislocation rate of $0 \%$ to $10 \%$ [13]. Spontaneous disenclavation of one haptic has been reported previously but no disenclavation were seen in our study $[10,27,28]$. If enclavation fails, it results in dislocation of the iris-claw IOL into the vitreous cavity $[14,27,28]$. Bading, et al. and Vote et al. found a retinal detachment rate of $6.3 \%$ to $8.2 \%$ and a choroidal haemorrhage rate of $3.2 \%$ after the implantation of a transsclerally sutured PC IOL. We did not observed such complications after implantation of retropupillary iris claw lenses, which is in agreement with findings in other studies [26,29]. Iris claw lens remained well centered in all our cases except one $[5,10,15]$. Pigment dispersion was seen as a complication in two studies, but this was not seen in several studies. We detected pigment dispersion in 12 cases (36.36\%) of our patients [15,27-30]. In our study we saw ovalisation of the pupil in 6 cases (18.18\%) as reported in previous studies. We encountered uveitis in 3 cases in our patients, in contrast with other studies $[10,14,15,27,28]$.

\section{Conclusion}

Retropupillary iris claw intraocular lens implantation is clinically safe, less time consuming, predictable and effective primary or secondary procedure in cases with deficient posterior capsule or inadequate capsular support. It is capable of delivering good visual outcomes with as many as $64 \%$ of patients with BCVA $\geq 6 / 12$ at 3 months follow up. After retropupillary Iris claw lens implantation the complications were minimal with several benefits as compared to Scleral fixated intraocular lens (SFIOL) and Anterior chamber intraocular lens (ACIOL). The endothelial cell loss was comparable to SFIOL and better than ACIOL with no cases of corneal decompensation. The endothelial cell loss was more intraoperatively with very little cell loss after 1 month of follow up.

Therefore, retropupillary iris claw lens implantation is a better alternative for scleral-fixed or angle-supported IOL implantation. 


\section{Open Access Journal of Ophthalmology}

\section{References}

1. Alpar J (1989) Present state of management of aphakia. Future of spectacles and contact lenses. Indian J Ophthalmol 37: 54-57.

2. Gicquel JJ, Langman ME, Dua HS (2009) Iris claw lenses in aphakia. Br J Ophthalmol 93(10): 12731275.

3. Uthoff D, Teichmann KD (1998) Secondary implantation of scleralfixated intraocular lenses. J Cataract Refract Surg 24(7): 945-950.

4. McCluskey P, Harrisberg B (1994) Long-term results using sclera fixated posterior chamber intraocular lenses. J Cataract Refract Surg 20(1): 34-39.

5. Hara S, Borkenstein AF, Ehmer A, Auffarth GU (2011) Retropupillary fixation of iris-claw intraocular lens versus transscleral suturing fixation for aphakic eyes without capsular support. J Refract Surg 27(10): 729735.

6. Hoh H, Ruprecht K, Nikoloudakis N, Palmowski A (1993) Preliminary results following implantation of iris-suture-fixated posterior chamber lenses. Ger J Ophthalmol 2(2): 70-75.

7. Lanzetta P, Menchini U, Virgili G, Crovato S, Rapizzi E (1998) Scleral fixated intraocular lenses; an angiographic study. Retina 18(6): 515-520.

8. Chang JH, Lee JH (1991) Long-term results of implantation of posterior chamber intraocular lens by suture fixation. Korean J Ophthalmol 5(1): 42-46.

9. Worst JGF, Massaro RG, Ludwig HH (1972) The introduction of an artificial lens into the eye using Binkhorst's technique. Ophthalmologica 164(5): 387389.

10. Mohr A, Hengerer F, Eckardt C (2002) Retropupillary fixation of the iris claw lens in aphakia. 1 year outcome of a new implantation techniques. Ophthalmologe 99(7): 580-583.

11. Hara T, Hara T (2004) Ten-year results of anterior chamber fixation of the posterior chamber intraocular lens. Arch Ophthalmol 122(8): 11121116.
12. Gonnermann J, Klamann MK, Maier AK, Rjasanow J, Joussen AM, et al. (2012) Visual outcome and complications after posterior iris-claw aphakic intraocular lens implantation. J Cataract Refract Surg 38(12): 2139-2143.

13. Anbari A, Lake DB (2015) Posteriorly enclavated iris claw intraocular lens for aphakia: long-term corneal endothelial safety study. Eur J Ophthalmol 25(3): 208-213.

14. Gicquel JJ, Guigou S, Bejjani RA, Briat B, Ellies P, et al. (2007) Ultrasound biomicroscopy study of the Verisyse aphakic intraocular lens combined with penetrating keratoplasty in pseudophakic bullous keratopathy. J Cataract Refract Surg 33: 455-464.

15. Baykara M, Ozcetin H, Yilmaz S, Timuçin OB (2007) Posterior iris fixation of the iris-claw intraocular lens implantation through a scleral tunnel incision. Am J Ophthalmol 144(4): 586-591.

16. De Silva SR, Arun K, Anandan M, Glover N, Patel CK, et al. (2011) Iris-claw intraocular lenses to correct aphakia in the absence of capsule support. J Cataract Refract Surg 37: 1667-1672.

17. Koch DD, Liu JF, Glasser DB, Merin LM, Haft E (1993) A comparison of corneal endothelial changes after use of Healon or Viscoat during phacoemulsification. Am J Ophthalmol 115(2):188-201.

18. Menezo JL, Martinez MC, Cisneros AL (1996) Irisfixated Worst claw versus sulcus-fixated posterior chamber lenses in the absence of capsular support. J Cataract Refract Surg 22(10): 1476-1484.

19. Koss MJ, Kohnen T (2009) Intraocular architecture of secondary implanted anterior chamber iris-claw lenses in aphakic eyes evaluated with anterior segment optical coherence tomography. $\mathrm{Br} \mathrm{J}$ Ophthalmol 93(10): 1301-1306.

20. Guell JL, Velasco F, Malecaze F, Vázquez M, Gris O, et al. (2005) Secondary Artisan-Verysise aphakic lens implantation. J Cataract Refract Surg 31(12): 22662271.

21. Odenthal MT, Sminia ML, Prick LJ, Gortzak-Moorstein N, Völker-Dieben HJ (2006) Long-term follow-up of the corneal endothelium after artisan lens implantation for unilateral traumatic and unilateral 


\section{Open Access Journal of Ophthalmology}

congenital cataract in children: two case series. Cornea 25(10): 1173-1177.

22. Rao R, Sasidharan A (2013) Iris claw intraocular lens: A viable option in monocular surgical aphakia. Indian J Ophthalmol 61(2): 74-75.

23. Weene LE (1993) Flexible open-loop anterior chamber intraocular lens implants. Ophthalmology 100(11): 1636-1639.

24. Drolsum L, Haaskjold E (1993) Secondary implantation of flexible open loop anterior chamber IOLs. Acta Ophthalmol 71(4): 482-486.

25. Malinowski SM, Mieler WF, Koenig SB, Han DP, Pulido JS (1995) Combined pars plana vitrectomylensectomy and open-loop anterior chamber lens implantation. Ophthalmology 102(2): 211-216.

26. Bading G, Hillenkamp J, Sachs HG, Gabel VP, Framme C (2007) Long-term safety and functional outcome of combined pars plana vitrectomy and scleral-fixated sutured posterior chamber lens implantation. Am J Ophthalmol 144(3): 371-377.

27. Wolter-Roessler M, Küchle M (2008) Correction of aphakia with retroiridally fixated IOL. Klin Monbl Augenheilkd 225(12): 1041-1044.

28. Kodjikian L, Beby F, Spire M, Gambrelle J, Hubert I, et al. (2006) Combined pars plana phacofragmentation, vitrectomy, and Artisan lens implantation for traumatic subluxated cataracts. Retina 26(8): 909916.

29. Vote BJ, Tranos P, Bunce C, Charteris DG, Da Cruz L (2006) Longterm outcome of combined pars plana vitrectomy and scleral fixated sutured posterior chamber intraocular lens implantation. Am J Ophthalmol 141(2): 308-312.

30. Menezo JL, Cisneros A, Hueso JR, Harto M (1995) Long term results of surgical treatment of high myopia with Worst- Fechner intraocular lenses. J Cataract Refract Surg 21(1): 93-98. 